\title{
Geriatrik Bilateral Transfemoral Amputede Stubbies Denemesi
}

\author{
Serap ALSANCAK $K^{1}$, Haydar ALTINKAYNAK ${ }^{1}$, Senem GÜNER ${ }^{1}$ \\ ${ }^{1}$ Ankara Üniversitesi Să̆lık Hizmetleri Meslek Yüksekokulu, Ankara, TÜRKIYE \\ E-mail: alsancak@ankara.edu.tr
}

\begin{abstract}
Özet
Bilateral alt ekstremite amputasyonları içerisinde transfemoral amputasyonlar nadir görülür ve nedenleri çoğunluklu diyabete bağlı vasküler hastalıklar ve travmadır. Geriatrik bilateral amputeler rehabilitasyon ekibinin ciddi mücadelesini gerektirir ve prostetik rehabilitasyon sürecini geciktirir.

Çalışmamızda Ankara Üniversitesi Sağlık Hizmetleri Meslek Yüksekokulu Protez ve Ortez Laboratuvarı'na Protez yapımı ve rehabilitasyonu için başvuran bilateral transfemoral ampulasyonlu bir hasta ele alınmıştır. Hastaya bilateral uygulanan stubby protezleri ile rehabilitasyondaki kazanım tartışılmıştır.
\end{abstract}

Anahtar Kelimeler: Transfemoral ampute, stubby, geriatrik ampute, rehabilitasyon, protez.

\section{Summary}

Bilateral transfemoral amputations are rarely in lower extremity amputations. The most common causes diabetic vascular disease and trauma. Geriatric bilateral amputees require the serious challenges of the rehabilitation team and delay the prosthetic rehabilitation.

Working on the geriatric bilateral transfemoral amputee to apply for manufacturing and rehabilitation in Ankara University Health Services Vocational School of Prosthetics and Orthotics Laboratory. Stubby prostheses was applied to the amputee and their won in rehabilitation was discussed.

Key words: Transfemoral amputee, stubby, geriatric amputee, rehabilitation, prosthesis. 


\section{Giriş}

Bilateral transfemoral amputasyonların bașta gelen nedenleri periferal vaskuler hastalık, savaș ve terör yaralanmaları, motosiklet, araç, tren kazaları gibi travmatik nedenler ile deprem, heyelan, çı̆̆ ve sel gibi doğal afetlerde göçük altında kalmalardır. Özellikle 55-95 yaşları arasında bilateral alt ekstremite amputasyonlarının en sık nedenleri diyabet ve vaskuler hastalıklardır. Cerrahi sonrası rehabilitasyon uygulamalarındaki gecikme, yapılamayan egzersizler ve mobilite kontraktürlerin gelişmesine zemin hazırlar. Bu durum geriatrik amputelerde aile bireylerine bağımlılığı ve depresyonu beraberinde getirir. Hastaların rehabilitasyonu ile uğraşırken çoğu kez bireyin diyabet, kordiyovasküler, respiratuvar hastalığg ile birlikte artriti, görme ve işitme problemleri ile de mücadele edilir (Engstrom ve Van de Ven, 1985; Smith et al, 1992; Uellendahl, 2004; Wainapel, 1985; Whitehouse, 1968). Amputasyon seviyesi ve yaş yükseldikçe amputenin tekerlekli sandalye tercihi de artar (Karmarkar, 2009). Bilateral çocuk amputeler düşme korkusu olmamasına bağlı stubbies ile yürüyüşlerinde erişkinlere göre çok kısa sürede başarılı olurlar (Kruger, 1990).

Fiziksel ve emasyonel karmaşık süreçle yüz yüze olan geriatrik bilateral ampute hastaların mobilizasyonlarında stabilite, denge ve enerji tüketimini azaltıcı prostetik tasarımları planlamak önemlidir. Yapılacak tercih ilerde amputede gelişebilecek kontraktürleri önleyecek veya gelişmiş olanları azaltıcı yönde kuvvetlerin oluşmasına katkı sağlayacaktır (Carroll, 2009; Crouse, 1990).

\section{Olgu Sunumu}

82 yaşında erkek A.K.'ya Mayıs 2000'de diyabete bağlı bilateral transfemoral amputasyon yapılmıştır. Pek çok kez bilateral transfemoral protezlerin uygulandığı ancak başarısız olunan ve ümitsizliğe kapılan hasta Mart 2013'de protezlerin yapımı ve protez eğitimi için Ankara Üniversitesi Sağlık Hizmetleri Meslek Yüksekokulu Protez ve Ortez Laboratuvarı'na tekerlekli sandalyede getirilmiştir. Hasta tekerlekli sandalye ile mobilizasyonda ve sandalyeden yatağa transferinde tam bağımsız değildir, bir miktar yardım almaktadır. Gövde fleksör ve ekstansör kasları (2), üst ekstremite gross kas testi $(3)^{+}$değerindedir. Bilateral kısa transfemoral amputede kalça fleksörleri (4), ekstansörleri (2) değerindedir. Her iki kalça da fleksiyon kontraktürü olup, sağda $20^{\circ}$ ve solda $10^{\circ}$ olarak tespit edilmiştir.

Ampute preprostetik dönemde genel mobilizasyon ve zayıf kaslara yönelik güçlendirme egzersizlerinin yer aldığı rehabilitasyon programına alındı, kontrakte kaslar için germe egzersizleri verildi. Güdük protez ölçü alımı öncesi elastik çorap ve bandajlarla ölçüye hazır konuma getirildi. Bilateral suction quadrilateral soketler hazırlanarak, kilitli geriatrik diz eklemli, diz üstü protezleri ile hastanın paralel barda mobilizasyonu sağlandı.

Paralel bar eğitiminde hastanın protez ayakları ters çevrilerek oluşan aşırı lumbal lordozu azaltıldı ve arkaya düşme eğilimi önlendi. Ancak yürüyüş sürecinde görülen instabilite, adım atmada aşırı zorlanma, aşırı efor harcama ve erken yorulma, kan basıncı ve solumdaki artış protezlerin "stubby" olarak planlanmasını gerektirdi. Stubbies uygulamasında protezlerde diz eklemleri ve pylonlar çıkarılarak SACH ayaklar doğrudan soketlere ters olarak tutturuldu. Hastanın yaklaşık bir ay paralel bar düzeyinde ve bir buçuk ay paralel bar dişında oldukça yoğun süren prostetik eğitimi ile güvenli, emniyetli ve stabil bir yürüyüş ancak iç ortamda sağlanabildi. Merdiven aktiviteleri ve diş ortamda yürüyüşün başarılamadığı amputede başarının tam sağlanamamasında prostetik faktörler kadar hastaya, iştirak eden hastalığına ve aileye bağlı faktörlerin bir kez daha önemi tespit edildi. 

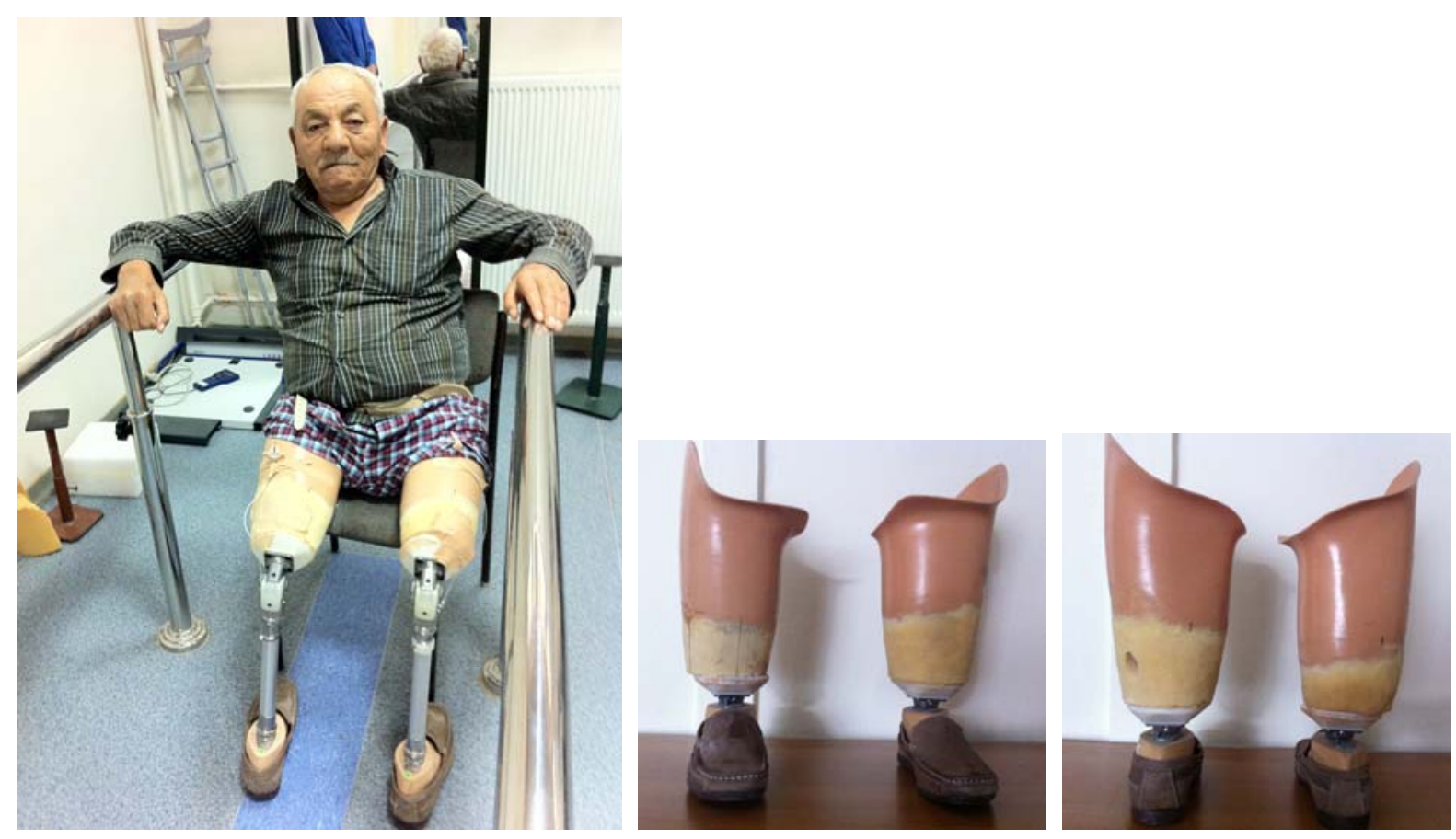

\section{Tartışma}

Alt ekstremite amputasyonlarında prostetik rehabilitasyonu vücut ağırlığının taşınma noktasının yere yakın olmas1 etkiler (Manella, 1981; May, 1996; Mc Coloughe et al.,1981). Bilateral transfemoral amputelerde daimi proteze geçilmeden önce veya güçlü kas yapısına sahip olmayan olgularda, geriatriklerde veya kalça kontraktürlerinde emniyet, stabilite ve enerji tüketiminde sorun yaşandığında "stubbies" uygulamasına gidilir. Stubby protezler, hafif malzemeden oluşturulan, boyu kısa tutulan, diz eklemi ve bacak bölümü bulunmayan, genellikle soketlerin altına rocker tipi ayakların bağlanarak hastaya özel oluşturulduğu protezlerdir (Balakrishnan, 1981; May, 1996; Smith, 1992) .

Geriatrik amputelerde stubbies uygulamalarına literatürde rastanmamakla birlikte az sayıda genç bilateral transfemoral amputeye daimi proteze geçmeden önce yapılmış stubby protez uygulamalarına rastlamak mümkündür (Balakrishnan, 1981; Bowers, 2008; Carroll, 2009; Gitter, 2002; Hoffman, 1997; Mc Coloughe et al., 1981; Smith et al, 1992; Uellendahl, 2004; Wainapel, 1985). Bu çalışmalarda da, bizim prostetik rehabilitasyon sırasında stubbies ile karşılaştığımız olumlu ve olumsuz yönler tespit edilmiştir. Örneğin stubbies ile mobilizasyon klasik proteze göre kolaydır, kan basıncı ve solunum sıklığı azdır, yürüyüş daha hızlıdır (\%25). Ayrıca yapılan çalışmalarda stubbies uygulaması ile enerji tüketiminin ve oksijen tüketiminin azaldığı gösterilmiştir (\%7-\%23). Kontraktürü önlemede etkilidir. Çalışmamızda her iki kalça kontraktürünün eğitim süresinde $5^{\circ}$ (sol)$7^{\circ}$ (sağ) azaldığı tespit edildi. Stubbies'lerin olumsuz yönü estetik olmaması, oturma sırasında sorun oluşturması ve sandalye boyunun kısaltılmasına veya özel tasarımlı koltuklara gereksinim duyulmasıdır. Nitekim çalışmamızda sert köpüklerden oluşturduğumuz oturma platformu ile sorunu çözümledik.

\section{Sonuç}

Tekerlekli sandalyeye bağımlı olan ancak yürüme arzusu bulunan, geriatrik amputeye bağlı faktörlerin klasik protezlerin tasarlanmasında yetersiz kaldığ durumlarda alternatif tasarım olarak "stubbies" uygulaması gerçekleştirilebilir. Ancak protezlerin yapımı ve prostetik eğitim sürecinde karşılaşılan 
sorunlar hastaya, ailesine ve rehabilitasyonunu üstlenen bireylere önemli görevler yükler. Multidisipliner tedavi yaklaşımı ve ekip üyeleri ile işbirliği ancak bu düzeyde bir başarıyı beraberinde getirebilmiştir.

\section{Kaynaklar}

Balakrishnan A. Technical note-tilting stubbies. Prosth and Orth International, 5: 85-87, 1981.

Bowers R. Standing alone again: bilateral above-knee amputee gets help from others to regain his in dependence and joy. In Motion. 2008; 18: 52-55.

Carroll K, Richardson R. Improving out comes for bilateral transfemoral amputees: A graduated approach to prosthetic success. The Academy Today, Online Learning Centre, 2009; 5(2).

Crouse SF, Lessard CS, Rhodes J, Lowe RC, Oxygen consumption and cardiac response of short-leg and longleg prosthetic ambulation in a patient with bilateral above-knee amputation: Comparison with able-bodied men. Arch Pyhs Med Rehab 1990; 71: 313-317.

Engstrom B, Van de Ven C. Physiothrapy for Amputees. London, Churchill Livingstore, 1985.

Gitter A, Paynter K, Walden G, et al. In fluence of rotators on the kinematic adaptations in stubby prosthetic gait. Am J Phys Med Rehabil, 2002; 81(4): 310-314.

Hoffman MD, Sheldahl LM, Buley KJ and Sandford PR. Physilogical comparison of walking among bilateral above-knee amputee and able-bodied subjects, and a model to account for differences in metabolic cost. Arch Phys Med Rehab, 78: 385-392, 1997.

Karmarkar AM, Collins DM, Wichman T, Franklin A et al. Prosthesis and wheelchair use in veterans with lower-limb amputation. Journal of Rehab Research and Development, 46(5): 567-576, 2009.

Kruger LM: Stubby prostheses in the rehabilitation of infants and small children with bilateral lower limb deficiencies. Rehabilitation, 1990; 29: 12-15.

Manella KJ. Comparing the effectiveness of bandages and shrinker socks for lower extremity amputees. Phy Ther 61: 334-337, 1981.

May BJ. Amputation and Prosthetics. Philadelphia, Davis Co, 1996.

Mc Colough NC, Harris AR, Hampton FL: The bilateral lower-limb amputee, In: Atlas of Limb Prosthetics, Surgical and Prosthetic Principles. Ed: Burgess EM. CV Mosby, St.Louis, 1981, pp. 417-422.

Smith DG, Burgess EM and Zett JH. Special Considerations: Fitting and training the bilateral lower limb amputee. In: Atlas of Limb Prosthetics: Surgical, Prosthetic and Rehab Principles, Eds: JH Bowker, JH Michael. $2^{\text {nd }}$ ed, CV Mosby, St Louis, 1992, pp. 599-623.

Uellendahl JE, Bilateral lower limb prostheses. In: Atlas of Amputations and Limb Deficiencies: Surgical Prosthetics and Rehabilitation Principles, Eds: DG Smith, JW Michael, JH Bowker. Rosemont, $3^{\text {rd }}$ ed, IL, 2004, pp. 621-632.

Wainapel SF, March H, Steve L: Stubby prostheses: An alternative to conventional prosthetic devices. Arch Phys Med Rehab 1985; 66: 264-266.

Whitehouse FW, Jurgensen C, Block MA: The later life of the diabetic amputee: Another look at the fate of the second leg. Diabetes 1968; 17: 520. 